\title{
UNUSUAL ELECTROCARDIOGRAM IN DEXTROCARDIA
}

\author{
BY
}

\section{J. M. HOLFORD}

Received February 4, 1944

The case here described was found in the course of a mass radiographic survey.

Case History.-The patient was a well-grown man aged 35 years. $\mathrm{He}$ was free from symptoms. He had no significant past medical history. He had always lived a normal life and had been moderately athletic in his school days.

On clinical examination it was found that cardiac pulsation was palpable in the right fourth intercostal space just internal to the mid-clavicular line. Normal heart sounds were heard in this area and between it and the sternum. At the left border of the sternum sounds were faint and further to the left were inaudible. No bruits were heard. There was no dyspnœa, cyanosis, clubbing of the fingers, or other indication of cardiac disorder. Blood pressure was $120 / 70$.

Radiography showed a heart in the position of complete dextrocardia, but otherwise of normal contour. The lung fields were clear. The left dome of the diaphragm was raised. The liver and stomach were not transposed.

Electrocardiographic Findings.-A cardiogram consisting of the three standard limb leads and three chest leads is shown in Fig. 1.
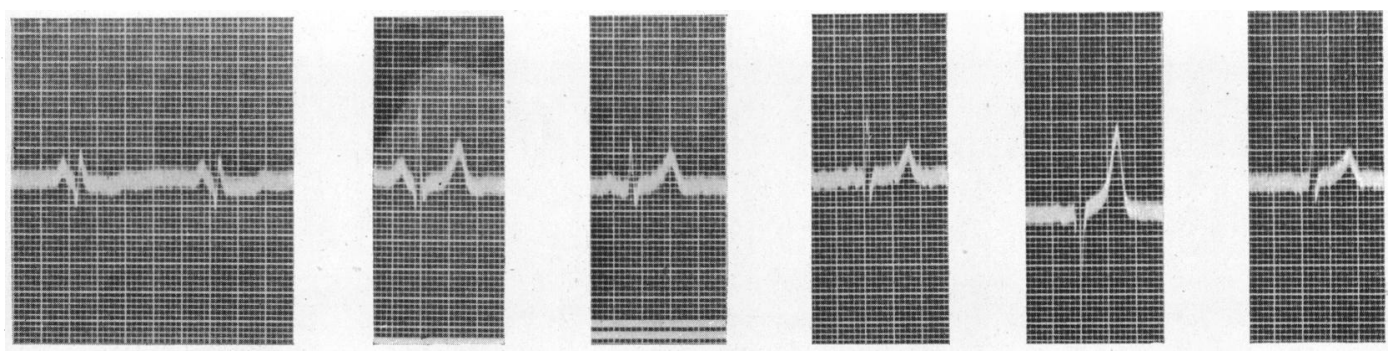

FIG. 1.-The standard leads I, II, and III are followed by CF1, CF2, and CF4 in that order, reading from the left. The chest leads have been taken in the mirror image of the normal position; thus, in CF1, the chest electrode is at the left border of the sternum, in CF2 at the right border, and in CF4 in the right midclavicular line; the neutral electrode is on the right leg.

In lead I, P is upright, the QRS complex shows a downward deflection followed by an upward one of approximately equal magnitude, and $\mathrm{T}$ is shallow and diphasic. All the remaining leads appear normal.

In their paper on the normal electrocardiogram Chamberlain and Hay (1939) gave no instances of an inverted $\mathbf{P}$ wave in lead $\mathrm{I}$, though it was sometimes so small as to be hardly visible. The accepted finding in dextrocardia, with or without situs inversus, is inversion of all waves in lead I. Katz (1941) and Pardee (1942) in their standard text-books of electrocardiography mention no other departure from the normal. Gross (1941), reporting four fresh cases in the course of a comprehensive review of dextrocardia, appears to regard complete inversion in lead $I$ as an invariable accompaniment of the condition. Beaujeu 
and Benmussa (1939), writing from Tunis, where dextrocardia is alleged to be much commoner than in Europe, have observed upright $P$ waves in lead I in a case complicated by the tetralogy of Fallot; they specifically state, however, that this does not occur in the absence of congenital heart disease. The low voltage $\mathrm{T}$ waves in lead $\mathrm{I}$ in the present case are also not mentioned by any of these writers.

I have to thank Surgeon Rear-Admiral F. J. D. Twigg for permission to publish this case.

\section{REFERENCES}

Beaujeu and Benmussa (1939). Arch. Mal. Cour, 32, 141.

Chamberlain, E. N., and Hay, J. D. (1939). Brit. Heart J., 1, 112.

Gross, L. (1941). J. med. Soc. New Jersey, 38, 354.

Katz, L. N. (1941). Electrocardiography, London, p. 269.

Pardee, H. E. B. (1942). Clinical Aspects of the Electrocardiogram, 4th edition, London, p. 256. 